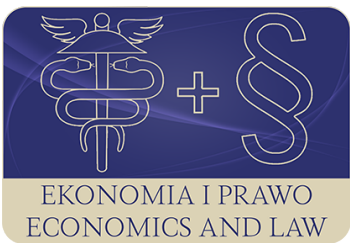

EKONOMIA I PRAWO. ECONOMICS AND LAW

Volume 16, Issue 3, September 2017

p-ISSN 1898-2255, e-ISSN 2392-1625

www.economicsandlaw.pl

EKONOMIA I PRAWO
ECONOMICS AND LAW

ORIGINAL ARTICLE

received 13.06.2017; revised 22.09.2017; accepted 30.09.2017

Citation: Batko, K. (2017). Relation between dynamic analytical capabilities and competitive advantage: theoretical approach. Ekonomia i Prawo. Ecomomics and Law, 16(3): 259-273.

doi:10.12775/EiP.2017.018.

\title{
Relation between dynamic analytical capabilities and competitive advantage: theoretical approach
}

\author{
KORNELIA BATKO \\ University of Economics in Katowice, Faculty of Economy, Department of Business Informatics, \\ ul. 1 Maja 50, 40-287 Katowice, Poland \\ $\square$ kornelia.batko@ue.katowice.pl
}

\begin{abstract}
Motivation: The contributory factor to undertake the subject was a research gap regarding the role of dynamic analytical capabilities in building competitive advantage of the organization. The analyzed issue is gaining in importance in an era of increasing requirements for the reinforcement of competitive position of organization, creation of unique resource

bundles, ability to access extremely rapidly growing amounts of data, development of business intelligence, big data analysis and even competition analyses. Many scientific papers and case studies have shown that Dynamic analytical capabilities (DAC) of the or-

ganization can provide benefits to organizations and create competitive advantage. Aim: The purpose of this paper is to identify dynamic analytical capabilities of the organization as an emerging research area on building a competitive advantage. Also the objective of this paper is to present theoretical model which describes the relationship between the three elements: dynamic analytical capabilities of the organization, analytical maturity and competitive advantage. In order to achieve the defined purpose, the critical literature analysis on dynamic analytical capabilities of the organization, analytical maturity and competitive advantage will be performed. Due to this fact, this paper presents a theoretical study.

Results: The article presents the concepts of dynamic analytic capabilities, considering factors that affect it. As a result of literature research, I constructed a theoretical model showing the relationship between the dynamic analytical capabilities and its determinants,

analytical maturity and competitive advantage. The results of studies led me to make the statement that the analytical maturity of the organization is a mediator of relationship

between dynamic analytical capabilities and competitive advantage of organization.
\end{abstract}


Keywords: dynamic analytical capabilities; analytics; competitive advantage; analytical organization; analytical maturity

JEL: D21; D89; J24

\section{Introduction}

One of the most important challenges faced by modern organization is the search for sources of their success, involving, among others, gaining and sustaining competitive advantage (Teece, 2007, pp. 1319-1350; Porter, 2011). Even though many authors emphasize that modern management faces many challenges (Renz \& Herman, 2016; Booth, 2015), the search for sources of competitive advantage of organization is still an interesting current topic of great relevance. Competitive advantage, according to strategic management classic theory, assumes that organizations that want to be better than the competition must create a set of resources and capabilities which satisfy the VRIO framework (V-Valuable, R-Rare, I-Inimitable, O-Organized to capture value). The issue that arouses growing interest is the concept of dynamic capabilities (Dynamic Capabilities View, DCV), which together with the resource theory (Resource Based View, RBV) as well as the relationship theory constitute the grounds for gaining and sustaining competitive advantage of organization.

The development of this trend brought impetus to the creation of conceptual works and empirical research on a variety of dynamic capabilities of contemporary organizations. Dynamic capabilities deserve mention in the following areas: supply chains (Fawcett et al. 2011, pp. 38-59; Beske, 2012, pp. 372387), innovations and production (Lawson \& Samson, 2001, pp. 377-400), marketing (Morgan et al., 2009, pp. 909-920; Mitrega \& Pfajfar, 2015, pp. 193-203), information technology (Bhatt \& Grover, 2005, pp. 253-277), or analytics and Business Intelligence (Davenport \& Harris, 2013; Olszak, 2014, pp. 1103-1110).

In this paper, the concept of dynamic analytical capabilities of the organization will be recognized due to the fact that, year by year, there is a growing number of scientific publications relating to the dynamic IT capabilities, Business Intelligence and analytical organizations. This rapid growth led to the lack of solid theoretical background. There are numerous studies that bring a plethora or theories and few of them, if any, are empirically verified. So far, papers and works accessible from the best datasets do not offer empirical research results of dynamic analytical capabilities that a researcher might call wellgrounded in a theory or carefully designed or well performed. The reason for such situation appears relatively simple - a broadly accepted theory on what are dynamic analytical capabilities and how it should be studied simply does not exist. In most cases, large number of studies seems unconfirmed and unverified in terms of theoretical conceptions. Thus, the need for the theory in dynamic analytical capabilities is apparent, but the theory must be based on substantial grounds made of research results. 
Analytical capabilities, derived from the concept of dynamic capabilities, can be defined as IT-enabled set of dynamic capabilities for improving decision making and company's performance. It is a specific and important type of IS capabilities. According to Gartner Group definition, analytical capabilities relate to information access and the analysis of decision-making style within an organization (Olszak, 2014, pp. 1103-1110).

\section{Literature review}

\subsection{Dynamic analytical capabilities of organization}

The issue that arouses a growing interest is the concept of dynamic capabilities (Dynamic Capabilities View, DCV), which together with the resource theory (Resource Based View, RBV) as well as the relationship theory constitute the grounds for gaining and sustaining competitive advantage of organizations. Most of theories to gain competitive advantage are based on the finding that a company should build their unique position in relation to the sector, including its structure, scarce resources, or relationships with external partners. The theory of competitive advantage of resources (Barney, 1991; Grant 1991; Rothaermel, 2015; Denrell \& Powell, 2016) postulates that building and sustaining competitive advantage should be based on the resources and key skills and competences. Therefore, companies can gain competitive advantage by acquiring and sustaining exceptional strategic resources and developing competences and capabilities. Increasingly, limitations of this concept are highlighted, namely focusing on company's owned resources as the single source of success, and neglecting the environment with emerging opportunities. In literature and business practice, there is noticed the existence of the complementary relationship between the different views, e.g. the resource-based view and relationship view (Mesquita et al., 2008, pp. 913-941; Mitrega \& Pfajfar, 2015, pp. 193-203). In response to discrepancies between these different approaches, the concept of dynamic capabilities has developed constituting a development of resources-based view (Hamel \& Prahalad, 1990, pp. 81-92; Teece et al., 1997, pp. 509-533; Kraaijenbrink et al., 2010, pp. 349-372).

The acquisition, configuration, reconfiguration, and development of available bundles of resources and key competences (or distinguishing capabilities) are essential factors for competitive advantage and the value creation (Olszak, 2014, pp. 1103-1110). It has developed in response to the shortcomings of the resource-based view, which takes the static positions linking a particular bundle of resources with the level of competitive advantage (Kozlenkova et al., 2014, pp. 1-21) and ignores changes in the turbulent environment. The static configuration of the bundle of resources cannot ensure a long-term competitive advantage, therefore organizations should adjust and reconfigure it to volatile conditions of the market environment. The resources available to the organ- 
ization is the first prerequisite for the value creation, the second is the ability to their efficient use in the process of generating values (Kozlenkova et al., 2014, pp. 1-21). In this approach, there is the opportunity to present dynamic capabilities as a set of identifiable processes, which relate to decision-making at the strategic level allowing for the complete use of the established strategic goals (options) (Eden \& Ackermann, 2013).

In the subject-matter literature there is no consensus on what dynamic analytical capabilities (DAC) are and what distinguishes them from other dynamic capabilities of organizations. In existing publications and research, the issue of dynamic analytical capabilities varies at the level of detail, and authors dealing with DAC often combine them with capabilities for Business Intelligence (BI) and specify them as dynamic capabilities BI (Popovic et al., 2012, pp. 729739; Isik at al., 2013, pp. 13-23) or Business Intelligence \& Analytics (BI\&A) (Davenport \& Harris, 2013; Olszak, 2014, pp. 1103-1110). This confirms the assumption that there are plenty of dynamic capabilities of organizations which can be complementary (Mitrega \& Pfajfar, 2015, pp. 193-203). Among the factors that were studied in the literature as the benefits of having extensive dynamic analytical capabilities, the following deserve mentioning: business performance, reputation, innovation, customer value, and competitive advantage. Some of these relationships have been considered only at the conceptual level.

Analytical capabilities, derived from the concept of dynamic capabilities, can be defined as IT-enabled set of dynamic capabilities for improving decision-making and company's performance. According to Gartner Group definition, analytical capabilities relate to information access and the analysis of decision-making style within an organization (Olszak, 2014, pp. 1103-1110). Davenport and Harris (2013) argue that analytical capability is a key element of strategy for the business. A contemporary creative analytical organization must be able to collect data, process them, analyse, and draw conclusions based on them. It must be emphasized, however, that management of the modern organization in the context of the technological challenges related to the search, acquisition, collection, selection, processing and application of information, is the extremely complex process. Therefore, it is necessary to implement appropriate information technology and develop in the organization the ability to operate these technologies as well as analyse skilfully data, draw conclusions of these analyses, and make appropriate decision based on them. Modern companies have, however, the chances for success by analysing the collected data, aimed at orientation to make strategic decisions (Davenport \& Harris, 2013).

In organization, two levels of dynamic analytical capabilities, namely organizational and individual level can be identified. Organizational level refers to the organization as a whole and is associated with the way of accessing and analysing information in the decision-making process within the organization. At the organizational level, dynamic capabilities are the opportunities that the organization obtained as a result of the integration, construction, reconfiguration of internal and external competence of employees, organizational 
knowledge and analytical technology in order to respond and adapt to changing environmental conditions quickly. Examples of dynamic analytical capabilities at organizational level are presented in table 1.

In turn, the individual level dynamic analytical capabilities apply to the human resources of their knowledge and skills. They were divided into two groups of dynamic analytical capabilities: soft and hard. The group of hard (technical) analytical capabilities includes knowledge and skills, which are quantitative, measurable attributes of employees needed to perform their work. Technical skills are primarily the ability to use the methods, techniques in a specialized analytical field. In turn, soft capabilities relate to psychophysical and social skills (Batko \& Billewicz, 2015, pp. 15-22). They focus on human behaviour, attitudes, way of living, and relate primarily to self-management, motivation, and interpersonal skills.

\subsection{Analytical maturity of the organization}

The contemporary management theories emphasise that there is a need for intensive and innovative use of information resources, which are considered as an important, strategic resource determining organization's success (Webster, 2014; Davenport \& Harris, 2013; Erickson \& Rothberg, 2013; Olszak, 2016, pp. 105-123). Supporting decision-making processes by data stored in the organization and its environment and analysis can help to raise its value to the business. This purpose can be facilitated by the implementation of organisational and technological solutions enabling fast and reliable assessment of the current situation and ensuring better use of increasing amounts of data. Technology refers to the development and use of computer hardware, software, and data analysis activities. It also covers the management of integrated systems, large databases, the integration of various analytical tools with other systems in the organization, conversion of data into information by visualization and reporting systems, and the use of advanced statistical tools to discover patterns, anticipate trends and optimize business processes (Olszak, 2014, pp. 1103-1110).

Moreover, seizing opportunities require investing not only in technology, but first in human capital, especially in analytical talents and Data Scientists that will be essential to obtain value embedded in data. Creating analytical capabilities in many organization can be a huge challenge but this will provide some scope for competitive advantage during the next decade. In literature, we can find some examples of benefits from the use of analytics in organization, but also sources of value from analytics. It can be both strategic value creation as well as efficiency improvement. Within these two areas we can distinguish faster decision-making, better quality decision, capability to take proactive actions, capability enhancement, automation, tools rationalization, and streamlined processes (scheme 1).

Organizations seek to acquire, create, and use appropriate technologies to gain competitive advantage in the global terms i.e. data warehousing, predic- 
tive modelling, data mining, web mining, agent systems, Business Intelligence and Analytics (BI\&A) systems, Competitive Intelligence, Big Data solutions, Collaborative Intelligence, advanced techniques within data filtering, social media, or specialized analytical software (Olszak, 2014, pp. 1103-1110). It is worth noting that RBV has been used extensively in IS (Information Systems) research to explain how IT assets provide value and sustainable competitive advantage to organizations (Olszak, 2014, pp. 1103-1110).

However, many companies that have the appropriate (sufficient) set of IT resources failed to ensure and sustain competitive advantage. Technology becomes a source of competitive advantage only when people can make use of it (Bhatt, 2001, pp. 68-75). Thus, dynamic analytical capabilities of the company do not keep pace with technological developments. Access to data and the technological infrastructure for the processing and analysing is not sufficient to generate effective analysis, and even more, to compete by the analysis and getting through them a competitive position. Most of the opportunities offered by the analytical systems are not applied because organizations expand capabilities related to the support of the information system and not the ability to analyse the data and correct inference. In order to determine if the analytical capabilities are developed in the organization at a sufficient level, the analytical maturity models are used. They are tools for determining an organization's analytical maturity level, understood as the level of development of analytical capabilities in specified areas (the strengths and weaknesses of a certain area within an organization are identified). Analytical maturity models are divided into levels or stages, and the idea is that the higher stage is reached when the requirements of all stages below are fulfilled. The organization achieves analytical maturity depending on the level at which the areas in the organization are developed within the key cross-sections: data (scope, availability, quality and data management capabilities at different business functions levels), technologies (quality and functionality of the technological infrastructure and analytical tools), processes (defining the relationship between analytical orientation of an enterprise and key business processes), organizational culture (determining the degree of development of analytical culture in an organization) and management (determining the level of integration of analytics with the organization strategy, decision making and ongoing activities). After reaching the full analytical maturity, analytical capabilities are becoming a strategic capability throughout the organization, and the organization has a coherent vision and strategy for integrating existing business intelligence initiatives.

The company geared to use analytics and dynamic analytical capabilities in building competitive advantage should strive to create a coherent vision and strategy of business intelligence initiatives, development of organizational culture, analytical skills, strategic knowledge, data, and technologies needed to try for the title of 'analytical competitor'. 


\section{Methods}

Therefore, the aim of this article is to present dynamic analytical capabilities as an emerging area of research on building competitive advantage of the organization. This purpose can be reached on the basis of a systematic and critical review of the literature on resource-based view, dynamic capabilities (DCV) and the dynamic analytical capabilities. Literature studies allowed me to identify a gap in the analysed area in conceptual and empirical areas. In order to achieve the purpose defined, the critical literature analysis on dynamic analytical capabilities of the organization, big data and analytical maturity as well as competitive advantage will be performed. The critical literature analysis on dynamic analytical capabilities of the organization will include three relevant areas of the literature: business analytics, resource-based view including dynamic capabilities and analytical maturity of organization. Due to this fact, this paper presents a theoretical study.

\section{Results}

Based on theoretical assumptions, it was possible to identify and characterize the factors influencing the dynamic analytical capabilities of the organization that are specified within the following groups: data, technology, people, organizational culture, governance, and processes (Mason, 2014) (scheme 2).

Table 2. presents the detailed factors determining the dynamic analytical capabilities of organization divided into the groups, presented in scheme 2.

Researchers agree that modern companies should build its competitiveness on the basis of their internal resources and the ability to adapt to changes in their environment. Such abilities provide organizations with a stable and sustainable development and contributes to building of their market value. To gain competitive advantage, companies use both hard resources (capital, technology, strategies and structure) and soft resources (socio-economic environment, knowledge and education to adapt the organization's environment). Changes in the environment cause that the importance of processes for rapid acquisition of new information and knowledge is growing and integration with the knowledge already held is necessary. Dynamic analytical capabilities of the company include a whole set of skills and technology, and it is synthesis of many diverse skills, technology and knowledge streams represented by all employees, creating a specific system (Batko \& Billewicz, 2015, pp. 15-22). At the business level, dynamic analytical capabilities are a key element of the strategy of the organization; they are also related to the way of accessing information and analysing it in the decision-making process (Davenport \& Harris, 2013).

This leads to the formulation of subsequent hypothesis $\mathrm{Hl}$ : The dynamic analytical capabilities of an enterprise are related to a competitive advantage.

Based on theoretical assumptions, it was possible to identify and characterize the factors influencing the dynamic analytical capabilities of the organization 
that are specified within the following groups: data, technology, people, organizational culture, governance, and processes (Mason, 2014; Olszak, 2014). Hence, I hypothesize what follows: Data, Technology, People, Culture, Management and Process are the determinants of dynamic analytical capabilities of the organization (H2).

Organizations may test if the analytical capabilities are developed in the organization at a sufficient level using the analytical maturity models (Davenport \& Harris, 2013). Organization achieves analytical maturity depending on the level at which the fields in the organization are developed within the key cross-sections: data, technologies, processes, organizational culture and management (Olszak, 2014). After reaching full analytical maturity, analytical capabilities are becoming a strategic capability throughout the organization and with it use the competitive advantage can be built (Davenport \& Harris, 2013). Thus, it leads me to propose following hypotheses: An analytical maturity of an organization characterized by analytical organizations is a mediator for the relation between dynamic analytical capabilities and competitive advantage (H3); Achieving a high level of analytical maturity influences the organization's competitive advantage $(\mathrm{H} 4)$.

These hypotheses allow creating the theoretical model presented in scheme 3. It is composed of four components: potential groups of determinants of dynamic analytical capabilities, dynamic analytical capabilities of the organization, analytical maturity of the organization and competitive advantage, and relationships between them. The relationships between these elements can be described using the above-mentioned four hypothesis.

Dynamic analytical capabilities of companies seem to comprise of the accurate approach contributing to improved competitiveness and as a source of creating new competitive advantages and foundation of technological development. The literature emphasizes that neglecting the development of the company's capabilities or core competences in the case of companies that are technologically sensitive results in rapid loss of competitive position and customer interest (Davenport \& Harris, 2013). Cultural barriers to enterprise-wide analytics adoption, such as the requirement for new leadership competencies and organizational resistance to new ideas, more than technology, are holding companies back from fully integrating analytics across their enterprises.

\section{Conclusion}

Concluding, it should be stated that gaining and sustaining competitive advantage based on resources is not an automatic and spontaneous process, but rather the result of the interaction of many elements of the company and its surroundings. Organizations, to ensure their long-term survival on the market, must possess the ability to operate efficiently and develop in the environment undergoing permanent changes. Confidence in achieving and sustaining constant competitive advantage of organizations is provided by their competences 
and dynamic capabilities, among them dynamic analytical capabilities seem to be of a key importance. Considering the issue of the use and analysis of data in organizations, one can see certain patterns and, on this basis, it is possible to make some generalizations about what distinguishes companies from each other, and these are dynamic analytical capabilities of the company. Analytics make significant impact on both performance and overall competitiveness, and that is why there is a need for organizations to implement a data-oriented culture and an analytics strategy that embeds fact-based insights into decisions and processes at every level of the organization.

The article presents the concepts of dynamic analytical capabilities, considering factors that influenced them. As a result of literature research, a theoretical model showing the relationship between the dynamic analytical capabilities, analytical maturity and competitive advantage was constructed. The results of studies led me to make the statement that the analytical maturity of the organization is a mediator of relationship between dynamic analytical capabilities and competitive advantage of organization. Future study will focus on the empirical verification of the research model presented (qualitative and quantitative research) to determine the impact of dynamic analytical capabilities on competitive advantage and to determine the role of analytical maturity in this relationship.

\section{References}

ATKearney. (2015). Gain advantage through analytics. Retrieved 20.02.2017 from https://www.atkearney.com.

Barney, J. (1991). Firm resources and sustained competitive advantage. Journal of Management, 17(1). doi:10.1177/014920639101700108.

Batko, K. \& Billewicz, G. (2015). Dynamiczne zdolności analityczne organizacji czynnikiem kreowania przedsiębiorczości. Przegląd Organizacji, 8.

Beske, P. (2012). Dynamic capabilities and sustainable supply chain management. International Journal of Physical Distribution \& Logistics Management, 42(4), doi:10.1108/09600031211231344.

Bhatt, G.D \& Grover, V. (2005). Types of information technology capabilities and their role in competitive advantage: an empirical study. Journal of Management Information Systems, 22(2). doi:10.1080/07421222.2005.11045844.

Bhatt, G.D. (2001). Knowledge management in organizations: examining the interaction between technologies, techniques, and people. Journal of Knowledge Management, 5(1). doi:10.1108/13673270110384419.

Booth, S.A. (2015). Crisis management strategy: competition and change in modern organizations. doi:10.4324/9781315645674.

Cosic, R., Shanks, G., \& Maynard, S.B. (2015). A business analytics capability framework. Australasian Journal of Information Systems, 19. doi:10.3127/ajis. v19i0.1150. 
Davenport, T., \& Harris, J. (2013). Competing on analytics: the new science of winning. Boston: Harvard Business Press.

Denrell, J., \& Powell, T. (2016). Dynamic capability as a theory of competitive advantage: contributions and scope conditions. In D.J. Teece \& S. Leih (Eds.), The Oxford Handbook of Dynamic Capabilities. doi:10.1093/ oxfordhb/9780199678914.013.007.

Eden, C., \& Ackermann, F. (2013). Making strategy: the journey of strategic management. London: Sage.

Erickson, G.S., \& Rothberg, H.N. (2013). A strategic approach to knowledge development and protection. The Service Industries Journal, 33(13-14). doi:10 $.1080 / 02642069.2013 .815740$.

Fawcett, S.E., Wallin, C., Allred, C., Fawcett, A.M., \& Magnan, G.M. (2011). Information technology as an enabler of supply chain collaboration: a dynamic capabilities perspective. Journal of Supply Chain Management, 47(1). doi:10.1111/j.1745-493X.2010.03213.x.

Grant, R.M. (1991). The resource-based theory of competitive advantage: implications for strategy formulation. California Management Review, 33(3). doi:10.2307/41166664.

Hamel, G., \& Prahalad, C.K. (1990). Corporate imagination and expeditionary marketing. Harvard Business Review, 69(4).

Isik, O., Jones, M.C., \& Sidorova, A. (2013). Business intelligence success: the roles of BI capabilities and decision environments. Information \& Management, 50(1). doi:10.1016/j.im.2012.12.001.

Kozlenkova, I.V., Samaha, S.A., \& Palmatier, R.W. (2014). Resource-based theory in marketing. Journal of the Academy of Marketing Science, 42(1). doi:10.1007/s11747-013-0336-7.

Kraaijenbrink, J., Spender, J.C., \& Groen, A.J. (2010). The resource-based view: a review and assessment of its critiques. Journal of Management, 36(l). doi:10.1177/0149206309350775.

Lawson, B., \& Samson, D. (2001). Developing innovation capability in organisations: a dynamic capabilities approach. International Journal of Innovation Management, 05(03). doi:10.1142/s1363919601000427.

Mason, N. (2014). Ingredientsfor an Analytical Organization. Retrieved 02.12.2014 from http://www.clickz.com.

Mesquita, L.F., Anand, J., \& Brush, T.H. (2008). Comparing the resource based and relational views: knowledge transfer and spillover in vertical alliances. Strategic Management Journal, 29(9). doi:10.1002/smj.699.

Mitrega, M., \& Pfajfar, G. (2015). Business relationship process management as company dynamic capability improving relationship portfolio. Industrial Marketing Management, 46. doi:10.1016/j.indmarman.2015.02.029.

Morgan, N.A., Vorhies, D.W., \& Mason, C.H. (2009). Market orientation, marketing capabilities, and firm performance. Strategic Management Journal, 30(8). doi:10.1002/smj.764. 
Olszak, C. M. (2016). Toward better understanding and use of Business Intelligence in organizations. Information Systems Management, 33(2). doi:10.1080 /10580530.2016.1155946.

Olszak, C.M. (2014), Towards an understanding Business Intelligence. A dynamic capability-based framework for Business Intelligence. In M. Ganzha, L. Maciaszek, \& M. Paprzycki (Eds.), Proceedings of the 2014 Federated Conference on Computer Science and Information Systems. doi:10.15439/2014F68.

Popovic, A., Hackney, R., Coelhoc, P.S., \& Jaklica, J. (2012), Towards business intelligence systems success: effects of maturity and culture on analytical decision making. Decision Support Systems, 54(1). doi:10.1016/j.dss.2012.08.017.

Porter, M.E. (2011). Competitive advantage of nations: creating and sustaining superior performance. Free Press: New York.

Renz, D.O., \& Herman R.D. (Ed.). (2016). The Jossey-Bass handbook of nonprofit leadership and management. Hoboken: John Wiley \& Sons. doi:10.1002/9781119176558.

Rothaermel, F.T. (2015). Strategic management. New York: McGraw-Hill.

Teece, D.J. (2007). Explicating dynamic capabilities: the nature and microfoundations of (sustainable) organization performance. Strategic Management Journal, 28(13). doi:10.1002/smj.640.

Teece, D.J., Pisano, G., \& Shuen, A. (1997). Dynamic capabilities and strategic management. Strategic Management Journal, 18(7). doi:10.1002/ (SICI)1097-0266(199708)18:7\%3C509::AID-SMJ882\%3E3.0.CO;2-Z.

Webster, F. (2014). Theories of the information society. London: Routledge. doi:10.4324/9780203426265.

\section{Acknowledgements}

Author contributions: author has given an approval to the final version of the article.

Funding: this research was fully funded by the University of Economics in Katowice, Faculty of Economy, Department of Business Informatics statutory sources.

Note: the results of this study were presented at 9th International Conference on Applied Economics Contemporary issues in Economy (June 22-23, Torun, Poland). 


\section{Appendix}

Table 1.

Examples of dynamic analytical capabilities at organizational level

\begin{tabular}{|c|c|c|}
\hline Author & Areas & Dynamic analytical capabilities \\
\hline $\begin{array}{l}\text { Olszak } \\
(2014)\end{array}$ & $\begin{array}{l}\text { governance, } \\
\text { culture, } \\
\text { technology, } \\
\text { people, } \\
\text { processes, } \\
\text { and change } \\
\text { management } \\
\text { \&creativity }\end{array}$ & $\begin{array}{l}\text { - business vision and plan } \\
\text { - business analysis planning and monitoring } \\
\text { - strategic alignment } \\
\text { - BI\&A and business strategy } \\
\text { - decision rights (operational, tactical, strategic) } \\
\text { - BI solution assessment and validation } \\
\text { - executive leadership and support } \\
\text { - flexibility and agility } \\
\text { - establishing a fact-based and learning culture } \\
\text { - data management } \\
\text { - systems integration and interaction with other systems } \\
\text { - flexibility } \\
\text { - reporting and visualization technology } \\
\text { - advanced bi technology (OLAP, data warehousing, data mining, predictive anal- } \\
\text { ysis) } \\
\text { - securing and building technology skills } \\
\text { - mathematical and statistical skills } \\
\text { - organizational skills } \\
\text { - organizational knowledge, knowledge sharing } \\
\text { - managing analytical people } \\
\text { - business interpersonal communication } \\
\text { - entrepreneurship and innovation } \\
\text { - trustworthiness } \\
\text { - holistic overview business process/knowledge processes } \\
\text { - business process/knowledge/modeling and orchestration } \\
\text { - process redesign and integration } \\
\text { - monitoring of competitors, customers and current trends in the marketplace } \\
\text { - generation of new and useful products, services, ideas, procedures, and processes }\end{array}$ \\
\hline
\end{tabular}




\begin{tabular}{|c|c|c|}
\hline Author & Areas & Dynamic analytical capabilities \\
\hline $\begin{array}{l}\text { Cosic et al. } \\
(2015)\end{array}$ & $\begin{array}{l}\text { governance, } \\
\text { culture, } \\
\text { technology, } \\
\text { people }\end{array}$ & $\begin{array}{l}\text { - decision rights } \\
\text { - evidence-based management } \\
\text { - data management } \\
\text { - technology skills and knowledge, strategic alignment } \\
\text { - embeddedness } \\
\text { - systems integration } \\
\text { - business skills and knowledge } \\
\text { - dynamic BA capabilities } \\
\text { - executive leadership and support } \\
\text { - reporting and visualisation } \\
\text { - BA technology } \\
\text { - management skills and knowledge } \\
\text { - change management } \\
\text { - flexibility and agility } \\
\text { - discovery BA technology } \\
\text { - entrepreneurship and innovation }\end{array}$ \\
\hline
\end{tabular}

Source: Own preparation based on Olszak (2014) and Cosic et al. (2015).

Table 2.

Potential determinants of the dynamic analytical capabilities of organizations

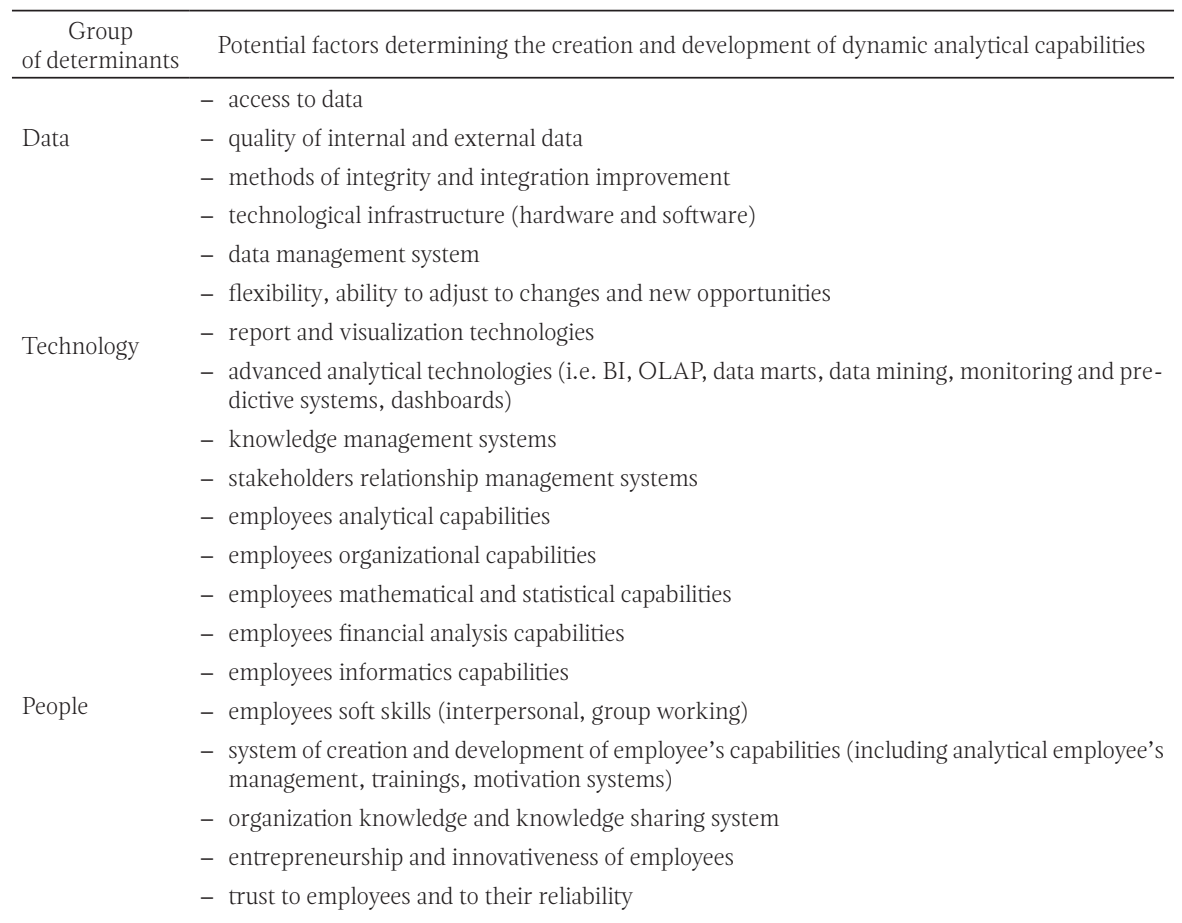




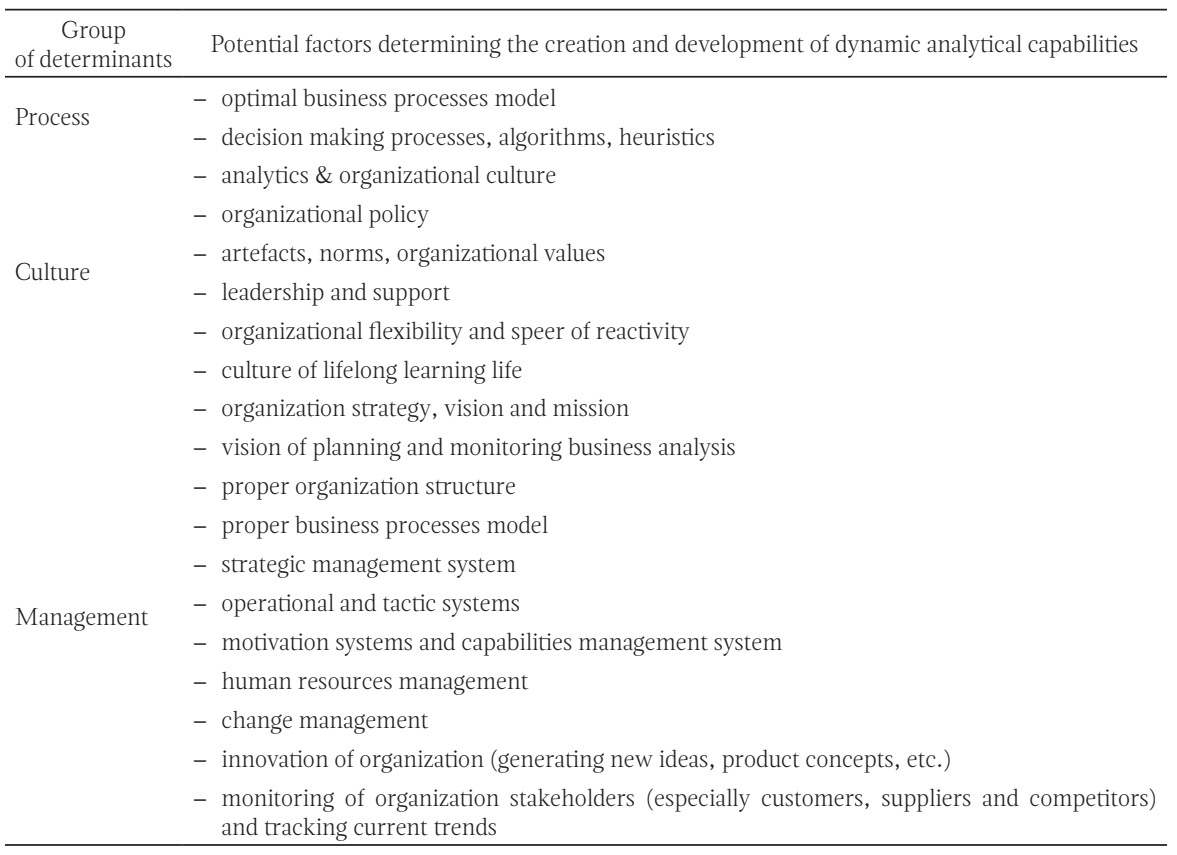

Source: Own preparation based on Olszak (2014), Mason (2014) and Davenport \&Harris (2013).

Scheme 1.

Drivers of analytical value

levers

drivers

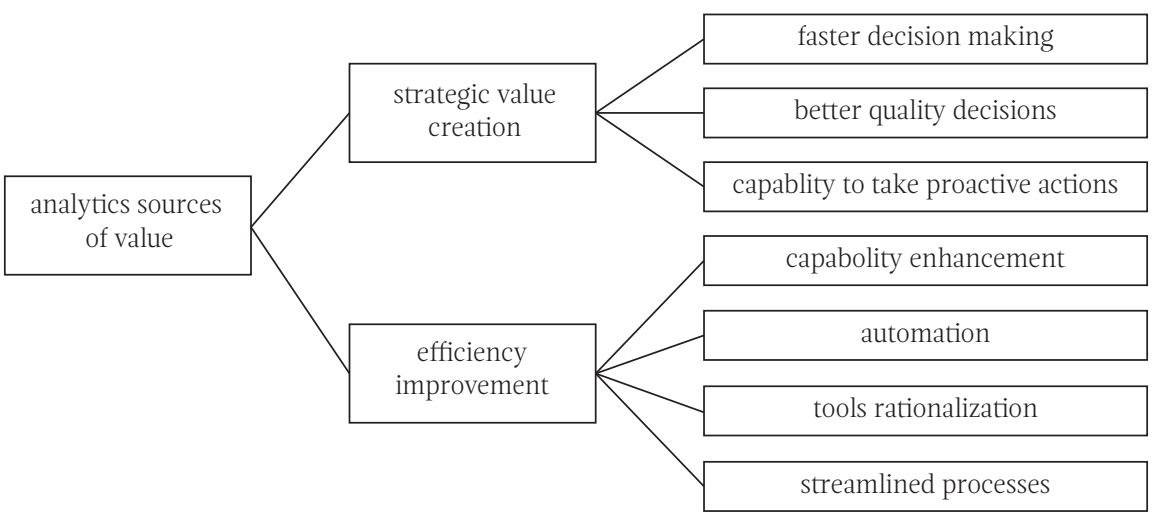

Source: ATKearney (2015). 
Scheme 2.

Specification of groups of dynamic analytical capabilities of organization

\section{Data}

quality, integration, integrity, easy access, mulitiple sources (internal end external)big data

Culture
analytical culture, organizational policies,
artefacts, norms, organization values,
leadership and support

Management

organization strategy, strategic management systems, innovation, change management, human resources management

\section{Technology}

infrastructure, data management system, data warehouses, analytical software and toots, system scalability and flexibility, reports and visualization, knowledge management

\begin{tabular}{|} 
People \\
analytical skills, managerial skills, motivation \\
systems, trainings, data scientist \\
\hline $\begin{array}{c}\text { Process } \\
\text { business process model, optimalization of } \\
\text { business processes, decision-making processes, } \\
\text { algorithms, heuristics }\end{array}$
\end{tabular}

Source: Own preparation based on Mason (2014).

Scheme 3.

The relationship between potential groups of determinants of dynamic analytical capabilities, dynamic analytical capabilities, analytical maturity, competitive advantage

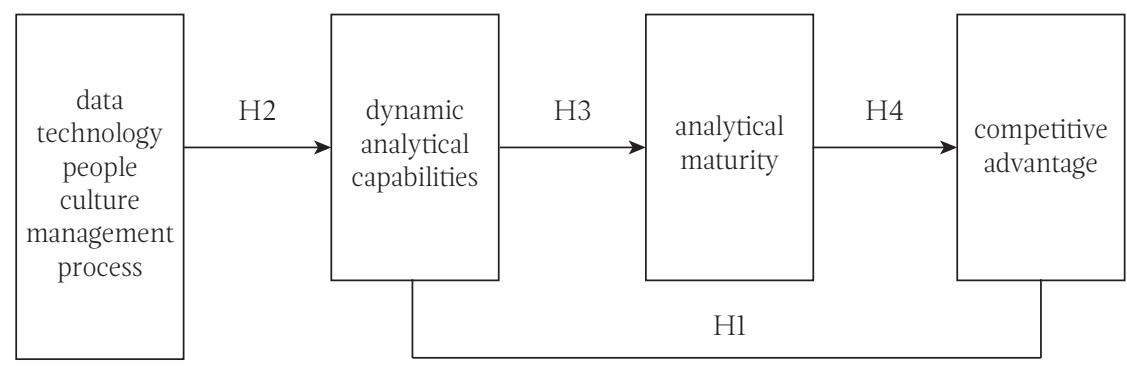

Source: Own preparation. 
